\title{
Extracellular expression and affinity purification of L-asparaginase from E. chrysanthemi in E. coli
}

\author{
Christos S Karamitros and Nikolaos E Labrou*
}

\begin{abstract}
Background: L-asparaginases (E.C.3.5.1.1, L-ASNases) are successfully used as anti-neoplastic agents in the chemotherapy of acute lymphoblastic leukemia (ALL) and therefore are of high interest for the medical and scientific community. In the present study we report the recombinant, extracellular expression and affinity purification of L-asparaginase from Erwinia chrysanthemi 3937 (ErL-ASNase) in E. coli.

Results: Recombinant E. coli strains were screened for their ability to express and translocate ErL-ASNase to the culture medium. The strain E. coli Rosetta (DE3) exhibited the highest extracellular expression levels among all the strains tested and it was chosen for further optimization and the development of purification protocol. Affinity adsorbents with immobilized L-Asn, L-Asp and L-Glu were synthesized by solid-phase chemistry and evaluated for their ability to bind and purify ErL-ASNase directly from the culture medium. The affinity adsorbent with immobilized L-Asp (L-Asp-Sepharose CL-6B) showed the highest purifying ability for ErL-ASNase. Adsorption equilibrium studies revealed that the adsorption of ErL-ASNase follows Langmuir isotherm with $\mathrm{K}_{\mathrm{D}}=0.21 \mu \mathrm{M}$ and maximum binding capacity $4.7 \mathrm{mg}$ enzyme/g moist wet adsorbent. This affinity adsorbent was used for the development of one-step purification protocol. The proposed protocol is simple, fast, gentle and afforded ErL-ASNase with high purity and yield.

Conclusions: We show that the recombinant expression of ErL-ASNase in E. coli results in the secretion to the culture medium due to the presence of its natural peptide leader at the N-terminus. We developed an L-Asp-based affinity adsorbent which allowed the purification of the enzyme in one step, achieving high purity levels. This approach is advantageous over the other conventional tag-based purification methods, which require additional treatment steps for the cleavage and isolation of the affinity tags. Overall, the strategy employed for expression and purification of this protein drug uses green chemistry principles allowing the reduction of processing time and purification steps, making the approach more sustainable and attractive.
\end{abstract}

Keywords: L-asparaginase, Enzyme purification, Extracellular expression, Leukemia, Therapeutic enzymes

\section{Introduction}

L-asparaginase (E.C.3.5.1.1, L-ASNase) catalyzes the hydrolysis of L-asparagine to L-aspartic acid and ammonia. The enzyme attracts attention due to its efficient use in the therapy of Acute Lymphoblastic Leukemia (ALL) [1-3]. L-ASNase is also used in combination with other drugs for the treatment of other type of malignancies such as nonHogkins Lymhoma, chronic lymphoblastic leukemia, lymphosarcoma, melanosarcoma $[4,5]$. In the case of ALL the therapeutic function of L-ASNase is due to the fact that the asparagine synthetase of the leukemic lymphoblasts is

\footnotetext{
* Correspondence: Lambrou@aua.gr

Laboratory of Enzyme Technology, Department of Biotechnology, School of Food, Biotechnology and Development, Agricultural University of Athens, lera Odos 75, 11855 Athens, Greece
}

downregulated resulting in deficiency of L-asparagine synthesis [6-8]. Therefore, the survival of those cells is dependent on the exogenous supply of L-asparagine from the blood. L-ASNase depletes the available L-Asn in the blood, causing inhibition of protein synthesis and apoptosis to the malignant cells $[8,9]$. It must be underlined that the normal cells are not affected since they can synthesize L-Asn.

L-ASNase is the only bacterial enzyme that has been approved by the FDA for human therapy [10]. The two approved preparations are from E. coli and E. chrysanthemi [11]. The E. coli ASNase is the first choice drug as it is capable of leading to remission very fast and causing relatively mild toxic effects [12]. Nevertheless, in cases where immunogenicity and allergic side effects 
arise due to E. coli L-ASNase, treatment is immediately switched to the Erwinia enzyme $[13,14]$. It has been reported, that the two enzymes exhibit totally different immunogenicity patterns in patients [15].

Affinity chromatography is considered to be one of the most refined and efficient techniques, which has been widely used in downstream processing with outstanding success in certain cases [16]. In this technique, the molecule of interest binds to another immobilized molecule, most often called the ligand. Ideally, the ligand has such structural and physicochemical properties that it is recognized specifically only by the target biomolecule [17]. As a result, the final purity depends on the specificity between the ligand and the biomolecule as well as, the strength of their interaction [18].

Periplasmic protein expression and potentially, extracellular secretion in the growth medium facilitates enormously the downstream processing protocol due to lower level of extracellular expressed proteins compared to intracellular ones [19-27]. As a result, higher protein purity can be achieved applying less number of chromatographic steps.

The long-term usage of L-asparaginase leads to lifethreatening multiple toxic effects. Among its multiple toxic effects, L-asparaginase induces allergic reactions usually due to low purity enzyme preparations and the presence of unwanted contaminations by bacterial proteins. Therefore, efficient recombinant expression, coupled with simple, rapid and low cost purification protocol would assist the overall production scheme of such an important enzyme, whose purity is extremely critical due to its use for human treatment. The aim of the present work is to study the optimization of the extracellular expression of ErL-ASNase in E. coli by attaching its natural peptide leader at the $\mathrm{N}$-terminus. The secreted recombinant LASNase was ultimately purified by applying an efficient one-step affinity chromatographic protocol.

\section{Experimental Materials}

L-Asn, L-Asp, L-Glu, trichloroacetic acid, 1,4-butanediol diglycidyl ether and crystalline bovine serum albumin (fraction V) were obtained from Sigma-Aldrich (U.S.A.).
Sepharose CL-6B were purchased from Pharmacia. Nessler's reagent was obtained from Fluka (Germany). Isopropyl-beta-D-thiogalactoside (IPTG) was from Genaxis (U.K.). Yeast extract, peptone, agar and glycerol were purchased from Scharlau (Spain).

\section{Solid phase synthesis of the affinity adsorbents}

Synthesis of the affinity adsorbents was carried using a two-step procedure as follows: i) Activation of agarose: Sepharose CL-6B beads (5 g) were thoroughly washed with double distilled water in a glass filter funnel and drained. The washed beads were suspended in $1 \mathrm{M}$ $\mathrm{NaOH}$ solution $(5 \mathrm{~mL})$ and shaken on a rotary shaker (140 rpm, $\left.25^{\circ} \mathrm{C}, 120 \mathrm{~min}\right)$. The beads were washed with double distilled water to remove excess $\mathrm{NaOH}$ and 1,4butanediol diglycidyl ether $(5 \mathrm{~mL})$ was added to the Sepharose CL-6B. The mixture was shaken at $140 \mathrm{rpm}$, $25^{\circ} \mathrm{C}$ for $12 \mathrm{~h}$. After completion of the reaction the 1,4butanediol diglycidyl ether-activated Sepharose CL-6B was washed with double distilled water.

ii) Coupling with the ligand (L-Asp, L-Glu, or L-Asn): Activated Sepharose CL-6B (5 g) was resuspended in 20 $\mathrm{mL} \mathrm{KH}_{2} \mathrm{PO}_{4}, \mathrm{pH} 7.5$, along with either L-Asp or L-Glu or L-Asn (1 g dissolved in $10 \mathrm{~mL} \mathrm{Na}_{2} \mathrm{CO}_{3}, \mathrm{pH} \mathrm{10).} \mathrm{The}$ mixture was shaken on a rotary shaker $\left(210 \mathrm{rpm}, 25^{\circ} \mathrm{C}\right)$ for $64 \mathrm{~h}$. After completion of the reaction, the gel was filtered, washed with distilled water and stored in water at $4^{\circ} \mathrm{C}$.

\section{Optimization of extracellular expression of ErL-ASNase in E. coli}

ErL-ASNase cloned in pCR T7/CT TOPO vector as described previously [28], was expressed in seven different E. coli strains (Table 1) in order to investigate the expression levels as well as potential secretion in the culture medium. A single colony of each $E$. coli strain harboring the recombinant plasmid [28] was used to inoculate LB medium containing $100 \mu \mathrm{g} / \mathrm{mL}$ ampicillin. Cultures were grown overnight at $37^{\circ} \mathrm{C}$ under vigorous rotation (240 rpm). Subsequently, either LB or $2 x Y T$ or TB main cultures supplemented with $100 \mu \mathrm{g} / \mathrm{mL}$ ampicillin, were inoculated with $1 / 100$ of overnight cultures. Cell growth

Table $1 E$. coli strains used in the present study

\begin{tabular}{|c|c|c|}
\hline E. coli strains & Genotypes & Supplier \\
\hline XL1-Blue & endA1 gyrA96 $\left(\right.$ nal $\left.^{R}\right)$ thi-1 recA1 relA1 lac glnV44 F' $:: T n 10$ proAB $^{+}$lacl $^{q} \Delta\left(\right.$ lacZ)M15] hsdR17 $\left(\mathrm{r}_{\mathrm{K}}^{-} \mathrm{m}_{\mathrm{K}}^{+}\right)$ & Stratagene \\
\hline TOP10 & $\begin{array}{l}\text { F- mcrA } \Delta(\text { mrr-hsdRMS-mcrBC) } \varphi 80 \text { lacZ } \Delta \text { M15 } \Delta \text { lacX74 nupG recA1 araD139 } \Delta \text { (ara-leu)7697 galE15 } \\
\left.\text { galK16 rpsL(Str }{ }^{R}\right) \text { endA1 } \lambda^{-}\end{array}$ & Invitrogen \\
\hline UT 5600 & $\mathrm{~F}^{-}$ara-14 leuB6 secA6 lacY1 proC14 tsx-67 $\Delta$ (ompT-fepC)266 entA403 trpE38 rfbD1 rpsL109 xyl-5 mtl-1 thi-1 & New England Biolabs \\
\hline $\mathrm{BL} 21(\mathrm{DE} 3)$ & $\mathrm{F}^{-}$ompT gal dcm lon hsdS ${ }_{B}\left(\mathrm{r}_{\mathrm{B}}^{-} \mathrm{m}_{\mathrm{B}}^{-}\right) \lambda(\mathrm{DE} 3$ [lacl lacUV5-T7 gene 1 ind1 sam7 nin5]) & Novagen \\
\hline BL21(DE3)Star & $\mathrm{F}^{-}$ompT gal dcm lon hsdS $\mathrm{B}_{\mathrm{B}}\left(\mathrm{r}_{\mathrm{B}}^{-} \mathrm{m}_{\mathrm{B}}^{-}\right) \lambda(\mathrm{DE} 3),\left(\mathrm{cm}^{\mathrm{R}}\right)$ & Invitrogen \\
\hline Rosetta(DE3) & $\mathrm{F}^{-}$ompT hsdSB $\left(\mathrm{r}_{\mathrm{B}}^{-} \mathrm{m}_{\mathrm{B}}^{-}\right) \mathrm{gal} \mathrm{dcm}(\mathrm{DE} 3)$ pRARE (CamR) & Novagen \\
\hline BL21(DE3)pLysS & $\mathrm{F}^{-}$ompT gal dcm lon hsdS ${ }_{B}\left(r_{B}^{-} m_{B}^{-}\right) \lambda(D E 3)$ pLysS $\left(\mathrm{cm}^{R}\right)$ & Novagen \\
\hline
\end{tabular}




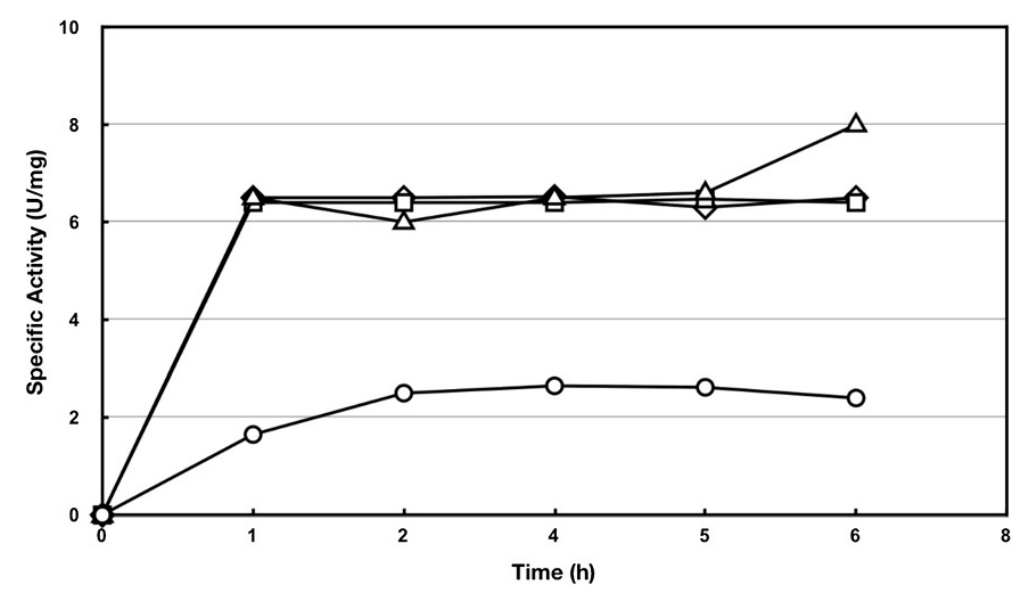

Figure 1 Evaluation of extracellular secretion of ErL-ASNase expressed by different E. coli strains ( $\triangle$ : E. coli Rosetta(DE3); $\diamond$ : E. coli BL21 (DE3) Star; $\square$ : E. coli BL21(DE3); O: E. coli TOP10). As time zero is considered the point at which IPTG is added. Cells were grown at $37^{\circ} \mathrm{C}$ as described in text. The standard deviation for the specific activities $(\mathrm{U} / \mathrm{mg})$, evaluated from three independent determinations was found to be less than $15 \%$.

was monitored spectrophotometrically and when absorbance at $600 \mathrm{~nm}$ reached $0.5-0.7$, expression was induced by the addition of IPTG to a final concentration of $1 \mathrm{mM}$. Cultures were incubated at $37^{\circ} \mathrm{C}$ or $18^{\circ} \mathrm{C}$ and at different time points cells were harvested by centrifugation at $10,000 \mathrm{~g}\left(4^{\circ} \mathrm{C}\right)$ for $20 \mathrm{~min}$, suspended in $50 \mathrm{mM} \mathrm{KH}_{2} \mathrm{PO}_{4}$ $\mathrm{pH} 7.5$, sonicated (the cell suspensions were divided into 2-mL fractions, which were sonicated by applying short pulses of $15 \mathrm{~s}$; the process was repeated three times), and centrifuged at $10,000 \mathrm{~g}\left(4^{\circ} \mathrm{C}\right)$ for $20 \mathrm{~min}$. The supernatant was collected and L-ASNase activity was determined in the intracellular extract as well as in the culture medium.

\section{Enzymatic activity assay}

Enzyme assays were performed at $37^{\circ} \mathrm{C}$ by measuring the amount of ammonia liberated upon reaction with Nessler's reagent. Activities were measured as described by Kotzia \& Labrou [28]. One unit of L-ASNase activity is defined as the amount of enzyme that liberates $1 \mu \mathrm{mol}$ of ammonia from L-Asn per min at $37^{\circ} \mathrm{C}$. Protein concentrations were determined at $25^{\circ} \mathrm{C}$ by the method of Bradford [29] using bovine serum albumin (fraction V) as standard.

\section{Screening of affinity adsorbents for ErL-ASNase binding}

Columns packed with affinity adsorbents $(2 \mathrm{~mL})$ were washed with $50 \mathrm{~mL}$ double distilled $\mathrm{H}_{2} \mathrm{O}$ and equilibrated with $30 \mathrm{~mL}$ of $20 \mathrm{mM} \mathrm{KH}_{2} \mathrm{PO}_{4}$, $\mathrm{pH}$ 7.5. Culture medium supernatant containing the secreted ErL-ASNase (approximately $80 \mathrm{U}$ ) was dialysed overnight against $20 \mathrm{mM}$ $\mathrm{KH}_{2} \mathrm{PO}_{4} \mathrm{pH} 7.5$ and was loaded onto each column. Nonadsorbent proteins were washed off with $30 \mathrm{~mL}$ of equilibration buffer. The adsorbent's binding capacity was determined as the proportion (\%) of L-ASNase (units) bound on the affinity adsorbent to the overall units loaded.

\section{Adsorption equilibrium studies}

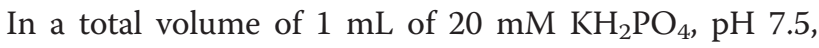
varying amounts of purified L-ASNase, previously dialysed in $20 \mathrm{mM} \mathrm{KH}_{2} \mathrm{PO}_{4} \mathrm{pH} 7.5$, were mixed with $3 \mathrm{mg}$ of affinity adsorbent (L-Asp-Sepharose CL-6B). The suspensions were shaken for $120 \mathrm{~min}$ in order for the system to reach equilibrium. The suspension was then

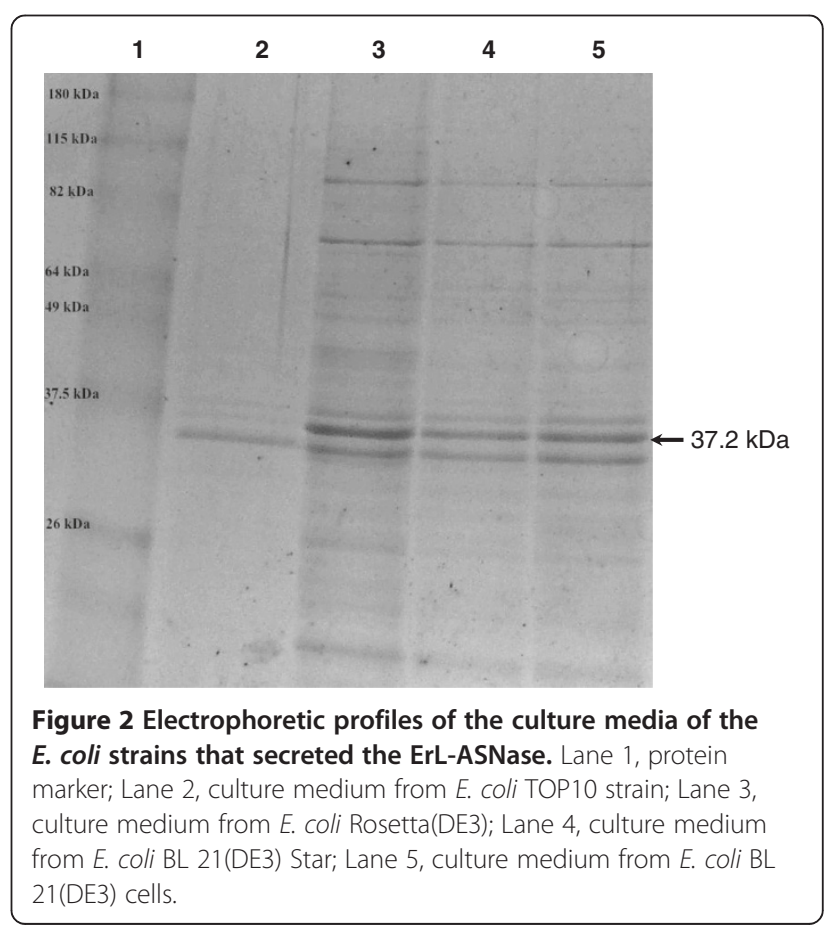




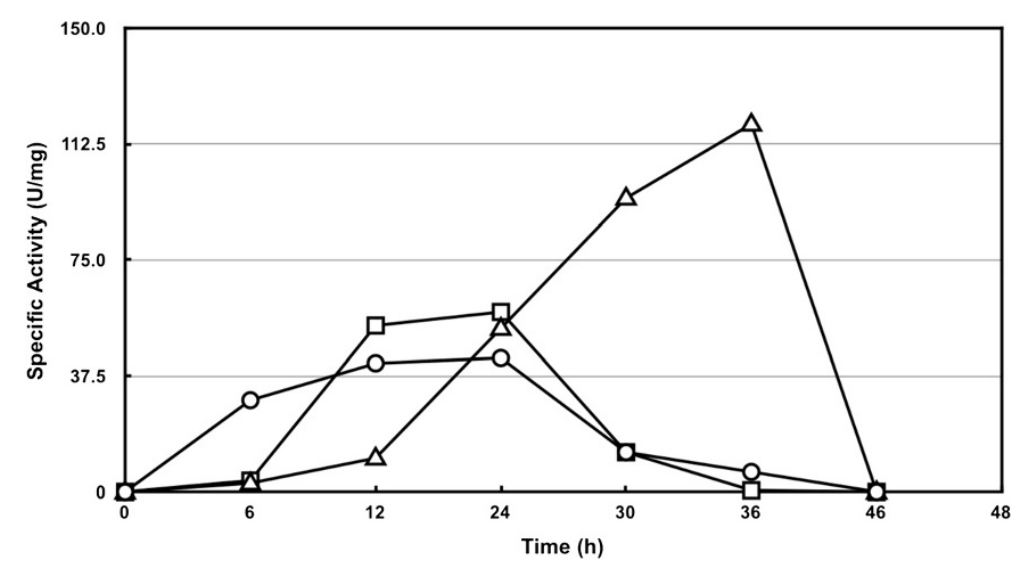

Figure 3 Supernatant specific activities of ErL-ASNase expressed in culture medium by $E$. coli Rosetta(DE3) strain using different culture media $(\triangle: \mathrm{TB} ; \square: \mathbf{2 x Y T} ; \mathrm{O}: \mathrm{LB})$ at $37^{\circ} \mathrm{C}$. The standard deviation for the specific activities $(\mathrm{U} / \mathrm{mg})$, evaluated from three independent determinations was found to be less than $15 \%$.

centrifuged (4000g, $2 \mathrm{~min}$ ) and the amount of unbound protein in the supernatant was determined by the Bradford method [29]. Bound protein was calculated by subtracting the amount of unbound protein from the total amount of protein added. The data were analyzed using Igor Pro software platform (Wavemetrics Co.).

\section{Purification of extracellular ErL-ASNase on immobilized L-Asp affinity adsorbent}

Culture medium $(10 \mathrm{~mL})$ was dialyzed overnight at $4^{\circ} \mathrm{C}$ against binding buffer $\left(20 \mathrm{mM} \mathrm{K \textrm {H } _ { 2 }} \mathrm{PO}_{4}, \mathrm{pH} 7.5\right)$ containing different concentrations of $\mathrm{NaCl}(0.05-0.2 \mathrm{M})$ and adjusted to different $\mathrm{pH}$ values (7.5-8.6) and loaded onto L-Asp adsorbent, previously equilibrated with $30 \mathrm{~mL}$ of the binding buffer. The column was kept closed for $10 \mathrm{~min}$ for the system to reach equilibrium. Subsequently, the column was exhaustively washed either with binding buffer containing $2 \mathrm{M} \mathrm{NaCl}$ or with ice-cold $\mathrm{ddH}_{2} \mathrm{O}$. Finally, bound ErL-ASNase was eluted with $10 \mathrm{~mL}$ of $20 \mathrm{mM} \mathrm{L}$ Asp dissolved in $20 \mathrm{mM}$ potassium phosphate buffer, $\mathrm{pH}$ 7.5. Both flow-through and washing fractions were kept and the protein content was determined by Bradford and analyzed by SDS-PAGE and activity assays.

\section{Electrophoresis}

SDS polyacrylamide gel electrophoresis was performed according to the method of Laemmli [30] on a slab gel containing $12.5 \%(\mathrm{w} / \mathrm{v})$ polyacrylamide (running gel) and $2.5 \%(\mathrm{w} / \mathrm{v})$ stacking gel. The protein bands were stained with Coomassie Brilliant Blue R-250.

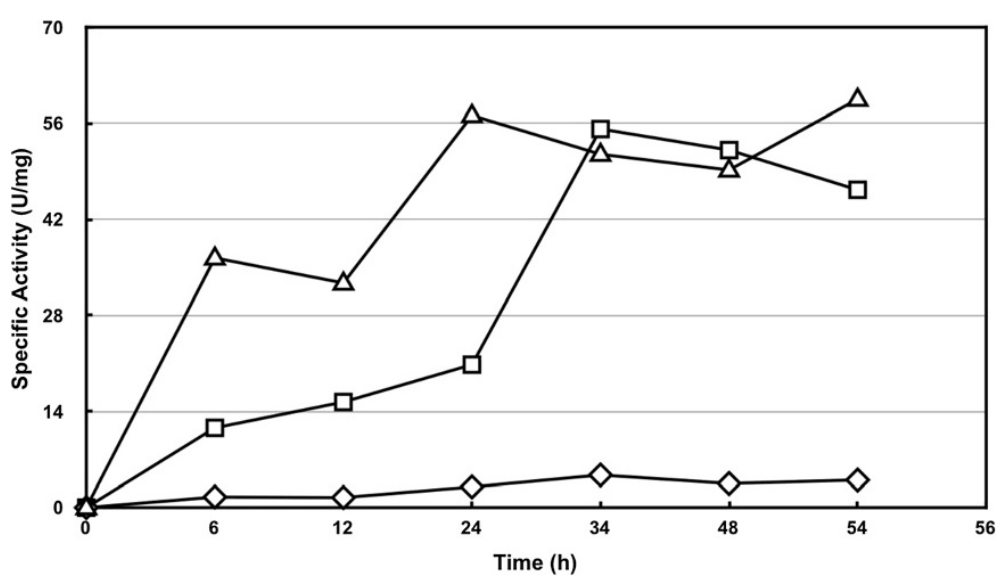

Figure 4 Supernatant specific activities of ErL-ASNase expressed in culture medium by $E$. coli Rosetta(DE3) strain using different culture media $(\diamond: \mathrm{TB} ; \square: 2 \mathrm{xYT} ; \triangle: \mathrm{LB})$ at $18^{\circ} \mathrm{C}$. The standard deviation for the specific activities $(\mathrm{U} / \mathrm{mg})$, evaluated from three independent determinations was found to be less than $15 \%$. 


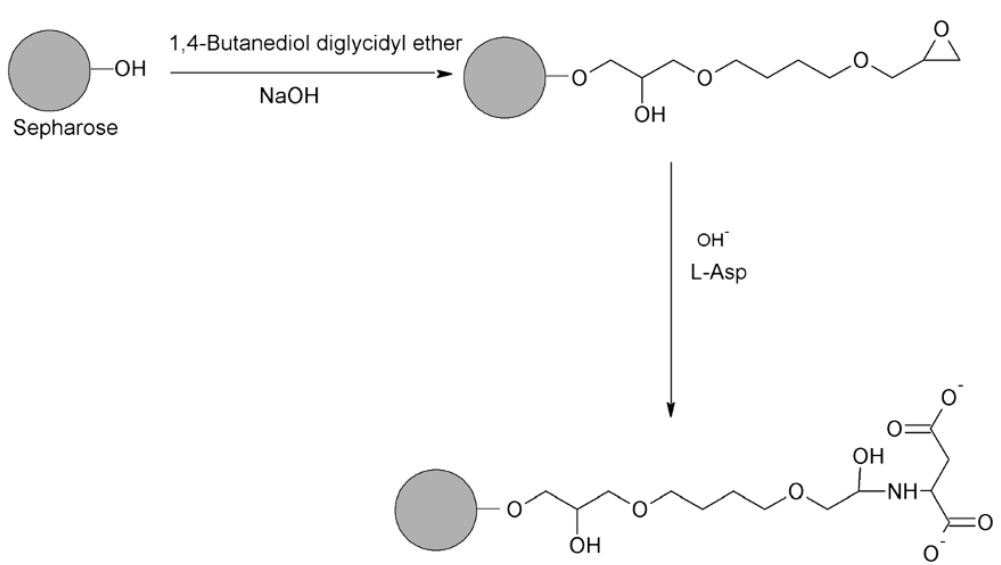

Figure 5 Solid phase synthesis of the affinity adsorbent with immobilized L-Asp as an example.

\section{Results \& discussion}

\section{Optimization of extracellular expression of ErL-ASNase} in E. coli

In order to investigate and determine the optimum conditions for extracellular expression of L-ASNase, seven $E$. coli strains (Table 1) were evaluated for their ability to secrete the recombinant enzyme into the culture medium, following induction by IPTG [31]. The results (Figure 1) showed that four [E. coli TOP10, E. coli BL21(DE3), E. coli BL21(DE3) Star, E. coli Rosetta(DE3)] out of seven strains were able to secrete recombinant ErL-ASNase into the culture medium at high level even during the early period of induction i.e. the first hour. Figure 2 shows the electrophoretic profile of the proteins secreted in the culture medium. It is evident that, the predominant protein band corresponds to ErL-ASNase $(\sim 37.2 \mathrm{kDa})$. Among all tested strains, E. coli Rosetta(DE3) secreted the highest amounts of ErL-ASNase, whereas E. coli TOP10 secreted the lowest. The other E. coli strains (XL-1 Blue, WT 5600, BL21(DE3)pLysS) failed to secrete ErL-ASNase and therefore, E. coli Rosetta(DE3) was chosen for further study. Three different culture medium compositions (LB, 2XYT and TB) and two different temperatures $\left(18^{\circ} \mathrm{C}\right.$ and $\left.37^{\circ} \mathrm{C}\right)$ were evaluated for their effect on the enzyme production and secretion, using the E. coli Rosetta(DE3) strain. As shown in Figure 3 the TB medium appears to provide the optimum conditions regarding the secretion of the enzyme, at $37^{\circ} \mathrm{C}$. Surprisingly enough, unlike $37^{\circ} \mathrm{C}$, TB was the worst at $18^{\circ} \mathrm{C}$ (Figure 4). Under these conditions approximately $17,800 \mathrm{UI} / \mathrm{L}$ of enzyme were secreted in the culture medium. On the other hand the intracellular expression level of ErL-ASNase was 4,200 UI/L.

\section{Synthesis and screening of affinity adsorbents for ErL-ASNase binding}

The synthesis of affinity adsorbents with immobilized LAsp, L-Asn and L-Glu was carried out on the solid phase
(Sepharose CL-6B) (Figure 5) according to the well established protocols [32]. Briefly, Sepharose CL-6B was activated by a bis-oxirane (1,4-butanediol diglycidyl ether) under alkaline conditions and the activated Sepharose CL6B was substituted by L-Asp, L-Asn and L-Glu at pH 10. In order to determine the most effective adsorbent, all adsorbents were evaluated for their ability to bind and purify ErL-ASNase from the extracellural medium. Dialyzed

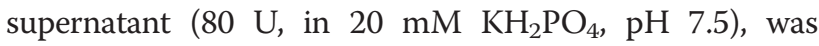
loaded on each adsorbent $(2 \mathrm{~mL})$. The columns were washed with equilibration buffer and bound ErL-ASNase was eluted with L-Asp $(20 \mathrm{mM})$ dissolved in $20 \mathrm{mM}$ $\mathrm{KH}_{2} \mathrm{PO}_{4}, \mathrm{pH}$ 7.5. It has been shown [33] that L-Asp is a strong competitive inhibitor $\left(\mathrm{K}_{\mathrm{i}} \sim 80 \mu \mathrm{M}\right)$ of L-ASNase. All affinity adsorbents were able to bind ErL-ASNase at pH 7.5 (Table 2). In particular, the adsorbent with immobilized L-Asp exhibited the highest binding capacity, followed closely by L-Glu, while L-Asn showed the lowest capacity. Taking into consideration the above observation, the adsorbent L-Asp-Sepharose CL-6B was selected for further study.

\section{Adsorption equilibrium studies}

In the present work, equilibrium adsorption studies were employed to characterize the interaction of ErL-ASNase with the L-Asp-Sepharose CL-6B affinity adsorbent. This approach gives a relationship between the concentration

Table 2 Binding (\%) of ErL-ASNase to the affinity adsorbents

\begin{tabular}{ll}
\hline Adsorbent & Binding (\%) \\
\hline L-Asn-Sepharose CL 6B & 49 \\
L-Asp-Sepharose CL 6B & 71 \\
L-Glu-Sepharose CL 6B & 59
\end{tabular}

Binding (\%) was expressed as the proportion (\%) of ErL-ASNase (U) bound on the affinity adsorbent to the overall units loaded. The standard deviation for the enzyme activities (U), evaluated from three independent determinations was found to be less than $10 \%$. 


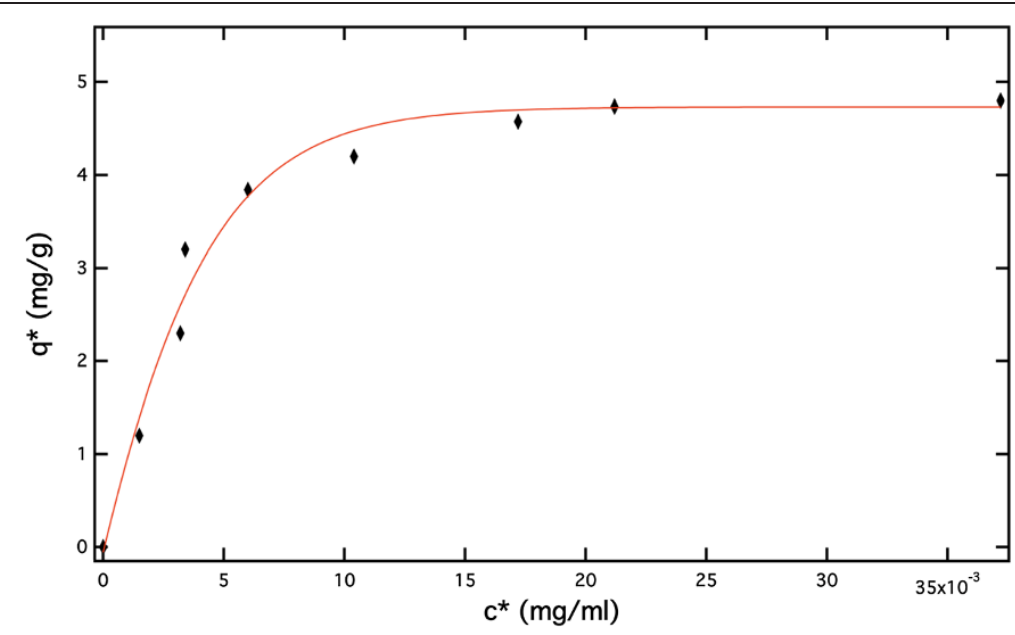

Figure 6 Equilibrium adsorption of ErL-ASNase on L-Asp-Sepharose CL-6B affinity adsorbent in batch system. The plot describes the equilibrium concentration of the enzyme in liquid-phase vs the equilibrium concentration in the solid-phase for the Langmuir isotherm. Non-linear regression curve fitting was performed using the Igor Pro software (Wavemetrics Co.).

of the enzyme in the solution and the amount of enzyme adsorbed to the adsorbent at equilibrium [17,32,34]. The theoretical model most often used to characterize affinity systems is the second-order reversible interaction, where the enzyme is bound to the ligand by a monovalent interaction (equation 1) that has a characteristic binding energy:

$$
\mathrm{E}+\mathrm{L} \underset{\mathrm{k}_{2}}{\stackrel{\mathrm{k}_{1}}{\rightleftharpoons}} \mathrm{E} . \mathrm{L}
$$

where $\mathrm{E}$ is the enzyme in solution, $\mathrm{L}$ is the ligand, and E.L is the enzyme-ligand complex. The parameters $k_{1}$ and $k_{2}$ are the forward and reverse rate constant, respectively. From equation 1 the Langmuir isotherm, described by equation 2 , can be obtained $[17,34]$ :

$$
\mathrm{q} *=\mathrm{q}_{\max } \mathrm{c} * /\left(\mathrm{K}_{\mathrm{D}}+\mathrm{c} *\right)
$$

where $\mathrm{q}^{*}$ is the adsorbate concentration at equilibrium (mg/g adsorbent), $\mathrm{c}^{*}$ is the equilibrium liquid phase concentration $(\mathrm{mg} / \mathrm{mL}), \mathrm{q}_{\max }$ is the Langmuir isotherm maximum capacity (mg/g adsorbent), and $K_{D}$ is the apparent dissociation constant.

The batch adsorption of ErL-ASNase on L-AspSepharose CL-6B affinity adsorbent is shown in Figure 6. The line corresponds to Langmuir isotherm which gives the best fit for the experimental data. The calculated dissociation constant was estimated to be $K_{D}=0.21 \mu \mathrm{M}$. This value falls within the range expected for a highly selective affinity adsorbent [35-37]. The maximum binding capacity $\mathrm{q}_{\max }$ was estimated $4.7 \mathrm{mg} / \mathrm{g}$ moist wet adsorbent.

\section{Purification of ErL-ASNase on immobilized L-Asp affinity adsorbent}

The challenge for the development of a purification protocol is to be considerably fast, gentle, low cost and efficient regarding yield and purity levels. Initial screening unveiled that the adsorbent L-Asp-Sepharose CL-6B displayed the higher capacity and purification ability for ErL-ASNase and consequently it was employed for the development of a purification protocol. It is noteworthy that bound ErL-ASNase on L-Asp adsorbent tolerated washing steps with even $2 \mathrm{M} \mathrm{NaCl}$ with negligible loss of protein. This is indicative of the strong binding of the enzyme on the affinity adsorbent. However, despite the fact that bound ErL-ASNase could resist against salt

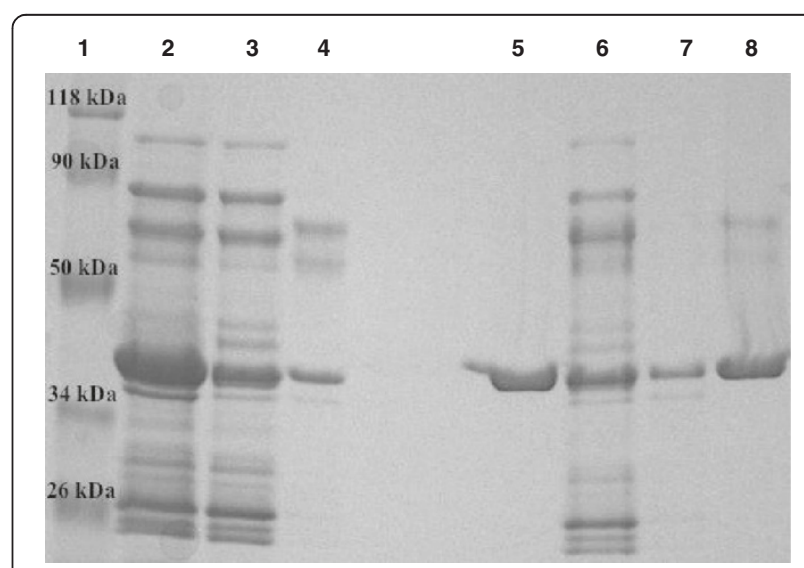

Figure 7 Electrophoretic profile of the purification protocol. Lane 1, protein marker; Lane 2, extracellular medium. Lane 3, flow through fraction; Lane 4, washing fraction, performed with $\mathrm{ddH}_{2} \mathrm{O}$; Lane 5, elution of ErL-ASNase after washing with $\mathrm{ddH}_{2} \mathrm{O}$; Lane 6, flow through fraction; Lane 7, washing fraction, performed with $2 \mathrm{M}$ $\mathrm{NaCl}$; Lane 8, elution of ErL-ASNase after washing with $2 \mathrm{M} \mathrm{NaCl}$. 
washing, up to $2 \mathrm{M} \mathrm{NaCl}$, unfortunately this step resulted in only moderate removal of non-specific bound contaminating proteins (Figure 7, Lanes 4,7). Other agents such as glycerol or sucrose that destabilizes hydrogen bond interactions between molecules, failed to remove non-specific bound contaminating proteins (data not shown). Surprisingly enough we found that nonspecific contaminating proteins can be totally removed after exhaustive washing with $\mathrm{ddH}_{2} \mathrm{O}$. This finding agreed with the observation that salt concentration $(0.1$ $\mathrm{M} \mathrm{NaCl}$ ) present in the binding buffer, maximized the binding specificity of the enzyme on the adsorbent at $\mathrm{pH}$ 7.5 (data not shown). The total absence of salt (as $\mathrm{NaCl}$ ) or salts at higher concentration $(0.2 \mathrm{M} \mathrm{NaCl})$ in this step resulted in a decrease in binding specificity. These findings led us to the development of single-step affinity purification procedure for ErL-ASNase. Dialyzed culture medium $\left(20 \mathrm{mM} \mathrm{KH} \mathrm{PO}_{4}\right.$, containing $0.1 \mathrm{M} \mathrm{NaCl}, \mathrm{pH}$ 7.5), was applied directly on L-Asp-Sepharose CL6B adsorbent, previously equilibrated with the dialysis buffer. Washing step included exhaustive washing with ice-cold $\mathrm{ddH}_{2} \mathrm{O}$. Elution of ErL-ASNase was affected specifically by $20 \mathrm{mM} \mathrm{L}$-Asp with a recovery $>80 \%$. The purity of the enzyme preparation was evaluated by SDS-PAGE (Figure 7, Lane 5) and shown to be homogeneous. The present method provides a simple and effective way for preparing in one-step highly purified recombinant ErL-ASNase.

\section{Concluding remarks}

Given the existing high interest in L-ASNase serving as a neoplastic agent and being a milestone for the treatment of ALL, we focused on the development of an efficient protocol for the expression and purification of this protein drug. The achievement of high purity levels in the case of pharmaceutical proteins is of great importance and plays a vital role in therapeutic applications $[38,39]$. Therefore, it is a challenging task to establish an efficient protocol not only for the recombinant expression of a therapeutic protein, but also for its purification, which must be simple, fast, mild and of low cost. Recently, L-ASNase from E. coli was extracellular expressed by fusing the gene coding for 6-His-tagged L-ASNase to the pelB leader sequence. In that work the recombinant 6-His-tagged protein was purified from the culture supernatant in a single step using Ni-NTA affinity chromatography $[40,41]$. However, this approach necessitates additional purification steps such as the cleavage and the removal of the 6-His-tag, which add to the overall cost of the purification process.

In the present work we showed that recombinant ErLASNase is efficiently expressed in E. coli Rosetta(DE3) and secreted into the culture medium. The expression levels were optimized by testing different $E$. coli strains, culture media, as well as temperature and incubation times. The secreted recombinant protein was purified directly from the culture medium, thereby simplifying considerably the downstream processing. The purification protocol was based on affinity adsorbent with immobilized L-Asp as a ligand, which exhibited high specificity and affinity for ErL-ASNase. The final purity of the enzyme (as judged by SDS-PAGE) justifies the potential for scaling up the whole process, taking also into account the low-cost materials used.

\section{Abbreviations}

ALL: Acute lymphoblastic leukaemia; L-ASNase: L-asparaginase; ErL-ASNase: L-asparaginase from Erwinia chrysanthemi 3937; FDA: Food and drug administration; GDH: Glutamate dehydrogenase; PAGE: Polyacryamide gel electrophoresis; SDS: Sodium dodecyl sulfate.

\section{Competing interests}

The authors declare that they have no competing interests.

\section{Authors' contribution}

CSK carried out the experimental work, analyzed the results and drafted the manuscript; NEL designed the experiments and drafted the manuscript. Both authors read and approved the final manuscript.

Received: 25 April 2014 Accepted: 24 July 2014

Published: 20 August 2014

\section{References}

1. Capizzi RL, Bertino JR, Skeel RT, Creasy WA, Zanes R, Olayon C, Peterson RG, Handschumacher RE: L-asparaginase: clinical, biochemical, pharmacological, and immunological studies. Ann Int Med 1971, 74:893-901.

2. Avramis Vl: Asparaginases: biochemical pharmacology and modes of drug resistance. Anticancer Res 2012, 32:2423-2437.

3. Labrou NE, Papageorgiou AC, Avramis VI: Structure-function relationships and clinical applications of L-asparaginases. Curr Med Chem 2010, 20:2183-2195.

4. Stecher AL, de Deus PM, Polikarpov I, Abrahao NJ: Stability of L-asparaginase: an enzyme used in leukemia treatment. Pharm Acta Helv 1999, 74:1-9.

5. Avramis VI, Spence SA: Clinical pharmacology of asparaginases in the United States: asparaginase population pharmacokinetic and pharmacodynamic (PK-PD) models (NONMEM) in adult and pediatric ALL patients. J Pediatr Hematol Oncol 2007, 29:239-247.

6. Keating MJ, Holmes R, Lerner S, Ho DH: L-asparaginase and PEG asparaginase-past, present, and future. Leuk Lymphoma 1993, 10:153-157.

7. Moola ZB, Scawen MD, Atkinson T, Nicols DJ: Erwinia chrysanthemi L-asparaginase: epitope mapping and production of antigenically modified enzymes. Biochem J 1994, 302:921-927.

8. Holleman A, den Boer ML, Kazemier KM, Janka-Schaub GE, Pieters R: Resistance to different classes of drugs is associated with impaired apoptosis in childhood acute lymphoblastic leukemia. Blood 2003, 102:4541-4546.

9. Appel IM, Kazemier KM, Boos J, Lanvers C, Huijmans J, Veerman AJ, van Wering E, den Boer ML, Pieters R: Pharmacokinetic, pharmacodynamic and intracellular effects of PEG-asparaginase in newly diagnosed childhood acute lymphoblastic leukemia: results from a single agent window study. Leukemia 2008, 22:1665-1679.

10. Cantor JR, Yoo TH, Dixit A, Iverson BL, Forsthuber TG, Georgiou G: Therapeutic enzyme deimmunization by combinatorial T-cell epitope removal using neutral drift. Proc Nat Acad Sci 2010, 108:1272-1277.

11. Patel N, Krishnan S, Offman MN, Krol M, Moss CX, Leighton C, van Delft FW, Holland M, Liu JZ, Alexander S, Dempsey C, Ariffin H, Essink M, Eden TOB, Watts C, Bates PA, Saha VJ: A dyad of lymphoblastic lysosomal cysteine proteases degrades the antileukemic drug L-asparaginase. Clin Invest 2009, 119:1964-1973. 
12. Bae N, Pollak A, Lubec G: Proteins from Erwinia asparaginase Erwinase ${ }^{\circledast}$ and $E$. coli asparaginase 2 MEDAC ${ }^{\oplus}$ for treatment of human leukemia, show a multitude of modifications for which the consequences are completely unclear. Electrophoresis 2011, 32:1824-1828.

13. Müller HJ, Beier R, Loning L, Blutters-Sawatzki R, Dorffel W, Maass E, Müller-Weihrich S, Scheel-Walter HG, Scherer F, Stahnke K, Schrappe M, Horn A, Lumkemann K, Boos J: Pharmacokinetics of native Escherichia coli asparaginase (Asparaginase medac) and hypersensitivity reactions in ALL-BFM 95 reinduction treatment. Br J Haematol 2001, 114:794-799.

14. Hak $\sqcup$, Relling MV, Cheng C, Pei D, Wang B, Sandlund JT, Rubnitz J, Pui CH: Asparaginase pharmacodynamics differ by formulation among children with newly diagnosed acute lymphoblastic leukemia. Leukemia 2004, 18:1072-1077.

15. Asselin BL: The three asparaginases: comparative pharmacology and optimal use in childhood leukemia. Adv Exp Med Biol 1999, 457:621-629.

16. Labrou NE: Design and selection of ligands for affinity chromatography. J Chromatogr B 2003, 790:67-78.

17. Labrou NE, Karagouni A, Clonis YD: Biomimetic-dye affinity adsorbents for enzyme purification: application to the one-step purification of Candida boidinii formate dehydrogenase. Biotech Bioeng 1995, 48:278-288.

18. Clonis YD: Affinity chromatography matures as bioinformatic and combinatorial tools develop. J Chromatogr A 2006, 1101:1-24.

19. Cornelis P: Expressing genes in different Escherichia coli compartments. Curr Opin Biotechnol 2000, 11:450-454.

20. Makrides SC: Strategies for achieving high-level expression of genes in Escherichia coli. Microbiol Rev 1996, 60:512-538.

21. Mergulhao F, Monteiro GJ: Secretion capacity limitations of the Sec pathway in Escherichia coli. Microb Biotechnol 2004, 14:128-133.

22. Wülfing C, Plückthun A: Protein folding in the periplasm of Escherichia coli. Mol Microbiol 1994, 12:685-692.

23. Shokri A, Sanden AM, Larsson G: Cell and process design for targeting of recombinant protein into the culture medium of Escherichia coli. Appl Microbiol Biotechnol 2003, 60:654-664.

24. Huang HC, Sherman MY, Kandror O, Goldberg AL: The molecular chaperone DnaJ is required for the degradation of a soluble abnormal protein in Escherichia coli. J Biol Chem 2001, 276:3920-3928.

25. Mergulhao F, Monteiro G, Kelly A, Taipa M, Cabral J: Recombinant human proinsulin: a new approach in gene assembly and protein expression. Microb Biotechnol 2000, 10:690-693.

26. Liao YD, Jeng JC, Wang CF, Wang SC, Chang ST: Removal of $\mathrm{N}$ - terminal methionine from recombinant proteins by engineered $E$. coli methionine aminopeptidase. Protein Sci 2004, 13:1802-1810.

27. Jones AJ: The use of an animal immunogenicity model in the development of Protropin somatrem (methionyl human growth hormone). Dev Biol 2002, 109:107-118.

28. Kotzia GA, Labrou NE: Cloning, expression and characterisation of Erwinia carotovora L-asparaginase. J Biotechnol 2007, 127:657-669.

29. Bradford MA: A rapid and sensitive method for the quantitation of microgram quantities of protein utilizing the principle of protein-dye binding. Anal Biochem 1976, 72:248-254.

30. Laemmli UK: Cleavage of structural proteins during the assembly of the head of bacteriophage T4. Nature 1970, 227:680-685.

31. Lee HC, Bernstein HD: The targeting pathway of Escherichia coli presecretory and integral membrane proteins is specified by the hydrophobicity of the targeting signal. Proc Nat Acad Sci 2001, 98:3471-3476

32. Platis D, Sotriffer CA, Clonis YD, Labrou NE: Lock-and-key motif as a concept for designing affinity adsorbents for protein purification. Chromatogr A 2006, 1128:138-151.

33. Jayaram HN, Cooney DA, Huang CY: Interaction between L-aspartic acid and L-asparaginase from Escherichia coli: binding and inhibition studies. J Enzyme Inhib 1987, 1:151-161.

34. Livingston AG, Chase HA: Preparation and characterization of adsorbents for use in high-performance liquid affinity chromatography. J Chromatogr 1989, 481:159-174.

35. Labrou NE, Clonis YD: Biomimetic-dye affinity chromatography for the purification of mitochondrial L-malate dehydrogenase from bovine heart. J Biotechnol 1996, 45:185-194.

36. Platis D, Maltezos A, Ma JK, Labrou NE: Combinatorial de novo design and application of a biomimetic affinity ligand for the purification of human antiHIV mAb 4E10 from transgenic tobacco. J Mol Recognit 2009, 22:415-424.
37. Platis D, Labrou NE: Affinity chromatography for the purification of therapeutic proteins from transgenic maize using immobilized histamine. J Sep Sci 2008, 31:636-645

38. Kotzia GA, Lappa K, Labrou NE: Tailoring structure-function properties of L-asparaginase: engineering resistance to trypsin cleavage. Biochem J 2007, 404:337-343.

39. Platis D, Drossard J, Fischer R, Ma JK, Labrou NE: New downstream processing strategy for the purification of monoclonal antibodies from transgenic tobacco plants. J Chromatogr A 2008, 1211:80-89.

40. Khushoo A, Pal Y, Singh BN, Mukherjee KJ: Extracellular expression and single step purification of recombinant Escherichia coli L-asparaginase II. Protein Expr Purif 2004, 38:29-36.

41. Khushoo A, Pal Y, Mukherjee KJ: Optimization of extracellular production of recombinant asparaginase in Escherichia coli in shake-flask and bioreactor. Appl Microbiol Biotechnol 2005, 68:189-197.

doi:10.1186/s40508-014-0016-z

Cite this article as: Karamitros and Labrou: Extracellular expression and affinity purification of L-asparaginase from E. chrysanthemi in E. coli. Sustainable Chemical Processes 2014 2:16.

Publish with ChemistryCentral and every
scientist can read your work free of charge
"Open access provides opportunities to our
colleagues in other parts of the globe, by allowing
anyone to view the content free of charge."
W. Jeffery Hurst, The Hershey Company.
- available free of charge to the entire scientific community
- peer reviewed and published immediately upon acceptance
- cited in PubMed and archived on PubMed Central
- yours - you keep the copyright
submit your manuscript here:
http://www.chemistrycentral.com/manuscript/

